\title{
Defined Adverse Event Subcategory Code
}

National Cancer Institute

\section{Source}

National Cancer Institute. Defined Adverse Event Subcategory Code. NCI Thesaurus.

Code C95357.

A coded value specifying a defined adverse event subcategory. 